\title{
Cardiac Function in Primary Myocardial Disorders*-Part II
}

\author{
JOHN F. GOODWIN, † M.D., F.R.C.P.
}

Brit. med. F., 1964, 1, 1595-1597

The data presented indicate that myocardial function in primary cardiomyopathy falls into three main groups: congestive, constrictive, and hypertrophic obstructive. However, clear-cut differences between the congestive and constrictive groups do not always exist, though the hypertrophic obstructive group appears to be different. In the congestive and constrictive groups the absence of any obvious cause for the heart disease and the finding of round-cell infiltration and fibrosis at necropsy in some would harmonize with an infective origin for many, though the histological and virological studies gave no support for this. Nevertheless, myocarditis or infective cardiomyopathy has long been accepted as an entity. Possibly infection damages the delicate contractile elements of the myocardium and interferes with the biochemical and biophysical phenomena essential for efficient function. In some way also the toxic agent might prevent the hypertrophy that occurs readily with most other forms of heart disease.

By contrast, the third group, hypertrophic obstructive cardiomyopathy, shows very marked differences from the other two, which strongly suggest another pathogenesis. A positive family history, massive ventricular hypertrophy, reduced ventricular compliance, disturbed contraction and systolic outflow gradients are associated with a high cardiac output and increased cardiac work.

My colleagues and I do not entirely agree with Björk et al. (1961), who maintain that in some cases abnormal attachment of the aortic cusps of the mitral valve may be a cause of obstruction to left ventricular outflow and of left ventricular hypertrophy.

Our studies, and those of others, indicate that the abnormalities in hypertrophic obstructive cardiomyopathy result in impaired ventricular filling and abnormal ejection, in addition to mitral incompetence in many patients. In contrast with the other groups congestive cardiac failure is unusual and occurred in only one patient in our series, though dyspnoea may be common and is attributable to an increased left atrial pressure secondary to increased left ventricular end-diastolic pressure resulting from rigidity of the left ventricle. Presumably for similar reasons tricuspid incompetence is unusual, but augmented "a" waves are common in the jugular venous pulse, and in a number of patients are accompanied by outflow systolic gradients. The inflow obstruction is presumably due to massive hypertrophy in addition to abnormal ventricular compliance. In some patients evidence of outflow obstruction is lacking, the characteristic ejection murmurs being absent, and obstruction is confined to ventricular inflow. Thus the diagnosis may depend on the characteristic angiographic appearances already described. It is these patients, perhaps, who are closest to the intermediate or unclassified group which has already been presented and which may represent a hypertrophic preobstructive stage of typical hypertrophic obstructive cardiomyopathy.

\section{Most Appropriate Definition}

Taking the term "obstructive" as indicating obstruction both to ventricular inflow and outflow we consider that obstructive cardiomyopathy is the most appropriate definition, but the addition of the word hypertrophic makes it clear that many patients have gross hypertrophy as the main feature rather than the extreme outflow tract obstruction that is stressed in many writings on this subject. Obstruction to right ventricular outflow probably results essentially from the massive septum bulging into the right ventricle. When the left ventricle contracts ejection is accomplished principally by a reduction in the diameter of the chamber, and by constriction of the cavity. There is, in addition, some shortening of the longitudinal axis (Rushmer, 1961), thus facilitating displacement of the septum into the right ventricle. It is easy to see how a systolic gradient could be created in this way. However, a gradient in the right ventricle can occur as a result of any condition that causes hypertrophy of the septum, and my colleague, Dr. Celia Oakley, has demonstrated such a gradient in patients with severe aortic valvar stenosis. Nevertheless, the obstruction to the rir.ht ventricle and the anomalies of right ventricular function in hypertrophic cardiomyopathy are not accounted for merely by hypertrophy of the septum. The angiographic findings indicating pockets of hypertrophied muscle and difficulty in ventricular filling suggest that the disorder of the muscle is generalized and involves the right ventricle in addition to the left.

Mitral incompetence is often present and is probably due to distortion of the mitral valve by hypertrophied and abnormally functioning ventricular muscle (Nordenström and Ovenfors, 1962). It appears to be associated especially with outflow gradients, and is absent in patients with little or no outflow obstruction. Our ciné-angiographic studies have shown that in this condition mitral incompetence occurs late in systole when outflow tract obstruction is maximal.

The mitral valve normally moves towards the apex during systole (Rushmer, 1961), and thus might be prevented from closing effectively if muscle at the apex of the left ventricle was grossly abnormal, as is the case in hypertrophic obstructive cardiomyopathy. By contrast, in congestive cardiomyopathy mitral incompetence when it occurs is due to stretching of the mitral valve ring as a result of generalized cardiac dilatation.

\section{Which comes First?}

We are not in a position yet to say whether the disorder of function precedes the hypertrophy or vice versa, or whether they occur concurrently. In considering the functional aspects of abnormal contraction in these patients it has already been suggested by Goodwin et al. (1961) and Bevegård et al. (1962) that the hypertrophied muscle contracts late, but it is important to recall the paper by Robb and Robb (1942) (quoted by Calvin et al., 1962), who, commenting on the deep bulbospiral muscle that encircles the base of the left ventricle, wrote " if the deep bulbospiral muscle contracted early, it would produce narrowing of the aortic outlet, and this would be equivalent to aortic stenosis. Since it contracts late it completes the emptying of the ventricle, supports the volume of blood in the aorta, and when it relaxes the aortic valves fall back in position and maintain the diastolic pressure."

If, as Robb and Robb suggested, the deep bulbospiral muscle contracted early, the shortening of the long axis that occurs

\footnotetext{
* The first part of this article, the tenth Strickland Goodall Lecture, was published last week.

† Professor of Clinical Cardiology, Postgraduate Medical School of London; Physician to Hammersmith Hospital.
} 
with left ventricular contraction might favour the production of gradients if considerable hypertrophy of the septum were present, and contraction were incoordinate in the various parts of the left ventricle. Early and abnormal contraction of the deep bulbospiral muscle might cause progressive septal hypertrophy, but the sharp upstroke of the aortic pulse suggests that early systole is not obstructed, so that incoordination between the deep bulbospiral muscle and other parts of the ventricle, rather than early contraction, is probably the cause. A vicious circle in which hypertrophy stimulates gradients and gradients favour hypertrophy may occur, for, as Brachfeld and Gorlin (1961) point out, the more the ventricle contracts the more obstruction it produces, and the presence of subvalvar muscular hypertrophy secondary to valvar stenosis is well recognized. However, at the moment these suggestions lie in the realm of hypothesis.

The influence of the cardiac nerves and the action of catecholamines on the myocardium may well be important in the light of the drug studies already described. The effect of catecholamines on ventricular function has been reviewed by Sarnoff and Mitchell (1961), who showed that at a fixed heart rate if the effective catecholamine stimulation remains constant the force of contraction of the ventricle varies proportionately with the fibre length and the end-diastolic pressure, and, conversely, if the end-diastolic pressure and fibre length remain constant the force of the contraction varies with the catecholamine stimulation. Excessive or abnormal catecholamine action on atria and ventricles might account for incoordinate contraction and abnormal diastolic function.

The contribution of atrial contraction to ventricular work has also been stressed by Sarnoff and Mitchell (1961), and it seems likely that the atrial hypertrophy that is so ccinrnon in hypertrophic obstructive cardiomyopathy assists ventricular contraction, and thus may tend to increase systolic gradients.

\section{Importance of Heart Rate}

The heart rate is also important in contributing to effective cardiac contraction in the presence of normal ventricular function. In patients with hypertrophic obstructive cardiomyopathy, isoprenaline, which increases rate, also produces gradients and lowers cardiac output, which is the reverse of what would be expected as a result of increasing the rate in the normal animal heart (Dale, 1930) and in the human heart, in which sudden increases in rate cause a more powerful contraction. In hypertrophic obstructive cardiomyopathy this powerful contraction probably occurs, but if it mainly involves the deep bulbospiral muscle it is likely to produce obstruction. Conversely, slowing of the rate is associated with reduction of the obstruction as shown by studies of the effects of phenylephrine and methoxamine. This could be due to prolongation of diastolic time which might allow rigid muscle more time to relax and thus fill the ventricle better, favouring more normal contraction in the next systole. Katz (1963) has stated that the important homoeostatic mechanisms controlling cardiac output are the end-diastolic volume, the systolic residue, and the heart rate. The end-diastolic volume is determined by four variables: the filling time, the systolic residue, the filling pressure, and the diastolic tone. Diastolic tone and systolic residue are likely to be increased in hypertrophic obstructive cardiomyopathy, and systolic tone; which is the end-systolic pressure divided by the end-systolic volume, may well be increased. If so, this would favour an increase in cardiac work, and haemodynamic studies have indeed revealed a high systolic ventricular pressure and a tendency to a high cardiac output.

It seems possible, therefore, that the heart in this condition operates at a high level of work with diminished compliance, and a high cardiac output. The abnormal contractile forces together with hypertrophy cause systolic pressure gradients. If this is true then cardiac function would be improved if the heart functioned at a lower level of ventricular work and lower minute volume, with a slower rate. This might result in reduction of gradients and perhaps a reduced tendency to angina, syncope, and sudden death.

It may be supposed that anginal pain is due to reduction in coronary blood-flow resulting from obstruction to inflow and outflow from the left ventricle, and syncope is the result of acute reduction in cerebral blood-flow from the same cause. Tachycardia, by reducing ventricular filling time, interfering with diastolic function, and increasing left atrial pressure, could explain dyspnoea on effort. Sudden death is presumably due to ventricular fibrillation resulting from acute coronary insufficiency as a result of obstruction to ventricular filling and emptying, potentiated by the tachycardia of exercise. Ventricular inflow and outflow obstruction are both influenced by abnormal muscular function and hypertrophy.

The jerky arterial pulse with pronounced tidal wave indicates that obstruction to left ventricular outflow is absent during the initial phases of ventricular contraction, which harmonizes with the late onset of the ejection murmur. The murmur probably has a dual origin. At the left sternal edge it is produced mainly or entirely by obstruction to left ventricular outflow, but at the apex is likely to be due to mitral incompetence. Ciné-angiographic studies have shown that mitral incompetence occurs late in systole, synchronizes with outflow obstruction, and has been noted only when outflow obstruction is marked. Thus, the murmurs of mitral reflux and of outflow block will be identical. Furthermore, in many patients there is outflow tract obstruction of the right ventricle which may also contribute to the systolic murmur.

The double apical impulse, like the fourth heart sound, is often due to the left atrium augmenting left ventricular function, but in some patients the second impulse may be due to abnormal late ventricular contraction. Mid-diastolic murmurs may be ascribed to inflow obstruction, and the augmented " $a$ " wave of the jugular venous pulse to right atrial hypertension secondary to right ventricular obstruction.

\section{Unclassified Group}

The unclassified or intermediate group represents an important facet of the primary cardiomyopathies. These patients tend to show hypertrophy of the ventricles without obstruction, and hence may well be early examples or variant forms of the fully developed hypertrophic obstructive group. Increasing knowledge of these disorders reveals their widening spectrum, and hypertrophic obstructive cardiomyopathy should always be considered in all patients with cardiomyopathy with evidence of marked cardiac hypertrophy, especially on the cardiogram, even if obstructive murmurs are absent. Congestive heart failure and atrial fibrillation, though always more suggestive of a congestive type of cardiomyopathy, do not exclude the hypertrophic obstructive variety.

The familial incidence in this and similar studies of hypertrophic obstructive cardiomyopathy, especially those of Paré et al. (1961) and other reports of cardiomyopathies of familial origin, suggest that a genetic abnormality of cardiac muscle may be the basic cause. Possibly an inherited developmental error in the function of the deep bulbospiral muscle or in the growth of cardiac muscle and in catecholamine function may be the original abnormality that could lead to the irregular ventricular hypertrophy (Fig. 19).

The genetic basis of the disease remains uncertain, but the lack of other developmental errors elsewhere in the body suggests that there is a single gene at fault rather than a complex chromosomal anomaly. The idea, suggested to me by Professor A. Huxley, of a fault in growth of the cardiac musculature, which perhaps develops irregularly, is attractive, for it would harmonize with the progressive nature of the disease. 
Lack of evidence of delayed relaxation of cardiac muscle suggests that an abnormality of the contractile proteins is unlikely.

Future research might profitably be diverted towards further studies of the effects of inotropic blocking drugs, studies of enzymes in normal and abnormal heart muscle, and examination of the gross pathology of the ventricular muscle bundles.

\section{OBSTRUCTIVE CARDIOMYOPATHY}

Possible mechanisms

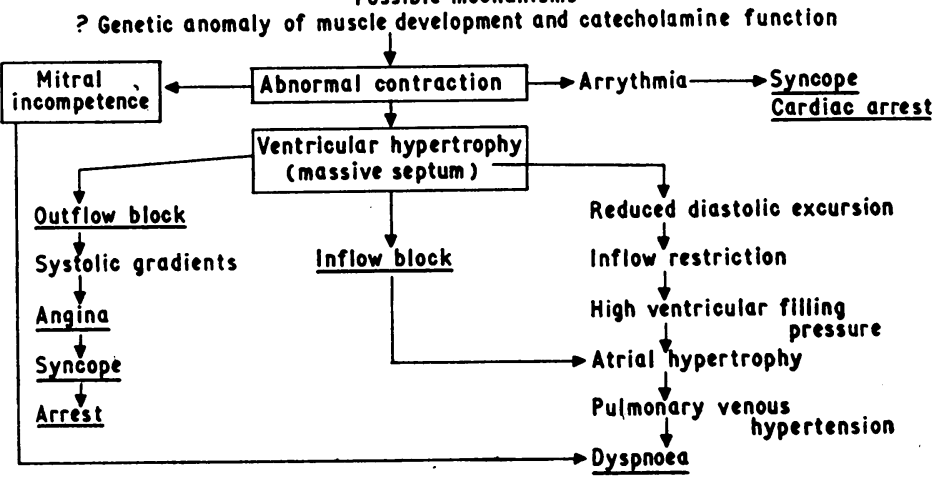

FIG. 19.-Possible mechanisms of obstructive cardiomyopathy.

Electronmicroscopical assessment of the structure of the abnormal muscle cells and a full genetic inquiry are also indicated.

\section{Summary}

The haemodynamic features have been studied in 48 patients with primary myocardial disease of unknown cause. The three main clinical groups-congestive, constrictive, and obstructive -have shown differences consisting of a flabby dilated heart with a low cardiac output and congestive heart failure in the first group, and similar features but with a smaller heart and impedance to ventricular filling in the second group. These two groups are not always sharply separated, and it is suggested that the cause may often be infective. By contrast, the obstructive group is characterized by massive ventricular hypertrophy and abnormal contraction of ventricular muscle, leading to disturbances both of ventricular inflow and outflow. There is a strong genetic influence in these cases, possibly involving some disturbance of endogenous catecholamine function.

It is a pleasure to acknowledge my debt to many colleagues in the past and present, particularly to Dr. Arthur Hollman, Dr. Celia Oakley, Dr. Jules Cohen, Dr. Donald Smith, Dr. Michael Dulake, Dr. Wendy Pocock, and Dr. Monica Bishop. Without the invaluable collaboration and advice of my radiological colleague, Professor Robert Steiner, much of this work would not have been possible. I would also like to thank Mr. W. P. Cleland and Mr. H. H. Bentall for their surgical wisdom, Dr. David Lewes for referring the first patient with hypertrophic obstructive cardiomyopathy to me, and many other friends for subsequently referring patients for investigation and treatment. I wish also to acknowledge the help of the Department of Medical Illustration of the Postgraduate Medical School, and of Mrs. P. Smy, who was responsible for the diagrams. I would also like to thank Mr. Gerald Rainbow and his cardiological technical staff, and the radiological and nursing staff of the angio- cardiographic and cardiac catheterization unit of the Postgraduate Medical School and Hammersmith Hospital for their unfailing assistance.

\section{REFERENCES}

Goodwin, J. F., Steiner, R. E., Hollman, A., and Oakley, C. M. (1962).C Proc. IV World Congress of Cardiology. In press. Clin., 28, 107.

McMichael, J. (1963). Brit. med. F., 2, 73.

Nye, R. E., jun., Lovejoy, F. W., and Yu, P. N. (1957). Circulation, 16, Robin, E. D., and Burwell, C. S. (1957). Ibid., 16, 730.

The above references do not appear in the text.

Bercu, B. A., Diettert, G. A., Danforth, W. H., Pund, E. E., jun., Ahlvin, R. C., and Belliveau, R. R. (1958). Amer. 7. Med., 25, 814.

Bevegård, S., Jonsson, B., and Karlöf, I. (1962). Acta med. scand., 172 269.

Björk, V. O., Hultquist, G., and Lodin, H. (1961). 7. thorac. cardiovasc. $\overrightarrow{\text { or }}$ Surg., 41, 659 .

Black, J. W., and Stephenson, J. S. (1962). Lancet, 2, 311.

Boiteau, G. M., and Allenstein, B. J. (1961). Amer. F. Cardiol., 8, 614. Bourassa, M. G., Boiteau, G. M., and Allenstein, B. J. (1962). Ibid., 10 UT 792.

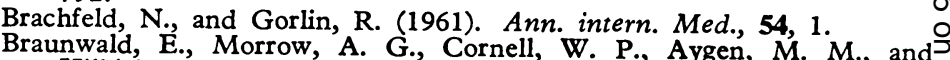
Hilbish, T. F. (1960). Amer. F. Med., 29, 924 . Aygen, M. M., and Brockenbrough, E. C., and Frye, R. L. (1962). Circulation, 26 166.

Brent, and Ebert, P. A. (1962). Amer. f. Cardiol., 10, 489. and Taylor, W. J. (1960). Circulation, 21, 167.

Brigden, W. (1957). Lancet, 2, 1179, 1243.

Brock, R. (1957). Guy's Hosp. Rep., 106, 221.

Brock, R. (1957)

Circulation, 23, 189.
Calvin, J. L., Perloff, J K Conta, E., and Morrow, A. G. (1961). O Amer. Heart f., 63, 477.

Cohen, J., Effat, H., Goodwin, J. F., Oakley, C. M., and Steiner, R. E.ฏ (1964). Brit. Heart $¥$., 26, 16 .

Dale, A. S. (1930). F. Physiol. (Lond.), 70, 455.

Dornhorst, A. C., and Robinson, B. F. (1962). Lancet, 2, 314.

Freundlich, E., Berkowitz, M., Elkon, A., and Wilder, A, (1958). 7. Dis. Child., 96, 43.

Goodwin, J. F Hollman, A. Cleland, W. P. and Teare, D. (1960 Brit. Heart f., 22, 403.

- Gordon, H., Hollman, A., and Bishop, M. B. (1961). Brit. medi 7., $1,69$.

Hollister, R. M., and Goodwin, J. F. (1963). Brit. Heart 7., 25, 357.

Hollman, A., Goodwin, J. F., Teare, D., and Renwick, J.' W. (1960) \& Ibid., 22, 449 .

Katz, L. N. (1963). Circulation, 28, 117.

Kirklin, J. W., and Ellis, F. H., jun. (1961). Ibid., 24, 739.

Kline, I. K., Kline, T. S., and Saphir, O. (1963). Amer. Heart F., 65ồ
446.

Krasnow, N., Rolett, E., Hood, W. B., jun., Yurchak, P. M., and Gorlin,o

Menges, H., jun., Brandenburg, R. O., and Brown, A. L. (1961). Circula N tion, 24,1126

Morrow, A. G., and Braunwald, E. (1959). Ibid., 20, 181.

Nord Brockenbrough, E. C. (1961). Ann. Surg., 154, 181.

Nordenström, B., and Ovenfors, C. O. (1962). Acta radiol (Stockh) 57,321 .

Paré, J. A. P., Fraser, R. G., Pirozynski, W. J., Shanks, J. A., and心్ట Stubington, D. (1961). Amer. F. Med., 31, 37.

Pearce, J. M. (1960). Circulation, 21, 448.

Robb, J. S., and Robb, R. C. (1942). Amer. Heart F., 23, 455.

Rushmer, R. F. (1961). Cardiovascular Dynamics, second edition $W$ Saunders, London.

Sarnoff, S. J., and Mitchell, J. H. (1961). Amer. F. Med., 30, 747.

Teare, D. (1958). Brit. Heart f., 20, 1. Teare, D. (1958). Brit. Heart f., 20, 1.
Whalen, R. E., Cohen, A. I., Sumner, R. G., and McIntoch, H. D足
(1963). Amer. F. Cardiol., 11, 8.

Wigle, E. D., Heimbecker, R. O., and Gunton, R. W. (1962). Circula $ᄋ$ tion, 26, 325.

- (1963). Brit. Heart 7., 25, 97. Chrysohou, A., and Bigelow, W. G. (1963). Amer. F. Cardiol., 11, 